\title{
Guidelines for Educational Research in Biochemistry on Internet Sites
}

\author{
Lima, R.M. ${ }^{1}$; Fernandes, K.V.S. ${ }^{2}$
}

1Lab. Biologia, IF Fluminense, Campus-Centro, RJ, ${ }^{2}$ LQFPP, UENF, RJ, Brazil.

The Internet has been used to support research in different areas, such as practical and educational research in medical and biomedical research. There are several recommended sites for carrying biomedical and medical research (BERGER, 2003). Nevertheless, few studies report on the use of the Internet in the teaching of Biochemistry. Considering the fact that there is no specific legislation for the use of the Internet in Brazil, it is necessary to stimulate self-regulation of the sector in order to establish minimum quality standards, safety, and reliability of sites containing information in the educational area. This study establishes some parameters to help guiding research for educational purposes on the internet. The following aspects should be checked: if the site has an editorial board responsible for content selection, and whether it is made up of experts in the area of expertise; if the site releases updated scientific materials, and provides pedagogical content that fosters teaching and learning such as images that contribute to the understanding of the content, educational software, and animation; if the site is recommended by universities, public and private qualified institutions. In addition, educational sites should present other aspects, including transparency (regarding their educational purpose), quality (scientifically based information), privacy (related to the user's personal data), responsibility and reliable sources. Such procedures are necessary to guarantee that searching for educational objectives will provide access to theoretical and pedagogical information quality .

Key-words: Internet, Education, Biochemistry.

Supported by: IFF Campus Campos-Centro. 
This document was created with Win2PDF available at http://www.win2pdf.com. The unregistered version of Win2PDF is for evaluation or non-commercial use only. This page will not be added after purchasing Win2PDF. 